\title{
Comparison of bevacizumab plus chemotherapy with chemotherapy alone in advanced non-small- lung cancer patients
}

This article was published in the following Dove Press journal:

OncoTargets and Therapy

27 July 2016

Number of times this article has been viewed

\author{
Ning Tang \\ Zhehai Wang \\ Department of Oncology, Shandong \\ Cancer Hospital and Institute, Jinan, \\ Shandong, People's Republic of China
}

Correspondence: Zhehai Wang Department of Oncology, Shandong Cancer Hospital and Institute, 440 Jiyan Road, Jinan, Shandong 250000 ,

People's Republic of China

Tel/fax+86 531 87984777

Email731060946@qq.com
Abstract: Bevacizumab plus chemotherapy was approved by the US Food and Drug Administration (FDA) as a first-line treatment for advanced nonsquamous, non-small-cell lung cancer (NSCLC) in 2006. This study retrospectively compared the efficacy of bevacizumab plus chemotherapy with chemotherapy alone as the first-line and second-line treatment as well as the maintenance treatment for advanced NSCLC patients. A total of 1,352 patients were included and we analyzed the efficacy evaluation according to the criteria of the Response Evaluation Criteria In Solid Tumors (RECIST), survival, and adverse reactions. The data showed that for bevacizumab plus chemotherapy as the first-line treatment, the median progression-free survival (mPFS) and median overall survival (mOS) were 11.5 and 17.0 months, respectively, compared to 7.0 and 14 months, respectively, in patients who received chemotherapy alone $(P<0.01)$. With bevacizumab plus chemotherapy as maintenance treatment, the mPFS and mOS were 6.0 and 17.4 months, respectively, compared to 3.0 and 15.0 months, respectively, with chemotherapy alone $(P<0.01)$. With bevacizumab plus chemotherapy as the second-line treatment, the mPFS was 3.0 months compared to only 2.0 months with chemotherapy alone $(P<0.01)$. The overall responses to the different regimens showed that the remission rate with bevacizumab plus chemotherapy was higher than that with chemotherapy alone $(31.8 \% \mathrm{vs}$ $25.5 \%, P<0.05)$, although there was no statistical difference in the disease control rate with either first- or second-line treatment. In conclusion, chemotherapy plus bevacizumab as the first-line and maintenance treatment, led to better curative rates and tolerable adverse reactions compared with chemotherapy alone in advanced NSCLC patients. Bevacizumab combined with cytotoxic drugs was suitable as the second-line treatment for such patients.

Keywords: non-small-cell lung cancer, bevacizumab, treatment efficacy, first-line treatment, second-line treatment, maintenance treatment

\section{Introduction}

Non-small-cell lung cancer (NSCLC) is one of the most commonly diagnosed solid tumors and the most common cause of cancer-related deaths in the world. ${ }^{1,2}$ NSCLC is mostly diagnosed at advanced stages (IIIB or IV) of the disease, making curable surgery rarely attainable, and leading to a poor prognosis. ${ }^{3,4}$ NSCLC patients are subjected to standard first-line chemotherapy with or without radiotherapy. ${ }^{5-7}$ Fortunately, the recent discovery of targeted therapy against an epidermal growth factor receptor (EGFR) mutation, the echinoderm microtubule-like protein 4-anaplastic lymphoma kinase (EML4-ALK), and angiogenesis opened a whole new chapter for clinical control of advanced NSCLC. To date, at least two Phase III clinical trials have demonstrated the efficacy of $E G F R$ tyrosine kinase inhibitor (TKI) with platinum-doublet chemotherapy 
as a first-line treatment for NSCLC patients with $E G F R$ mutation, ${ }^{8,9}$ and the efficacy and safety of crizotinib, which targets ALK, was also tested in NSCLC patients through a series of clinical trials named PROFILE. ${ }^{10-13}$ These targeted therapy regimens focus on EGFR mutation; however, a previous study including 1,482 patients from seven Asian countries demonstrated that the EGFR mutation rate was $51.4 \%{ }^{14}$ and the prevalence of ALK rearrangements was between $3.3 \%$ and $11.6 \%$ in the Chinese patients, ${ }^{15-17}$ a range which is similar to that observed in other Asian patients. ${ }^{18,19}$ Thus, identification and development of other targeted therapeutic strategies, such as those against angiogenesis, could lead to better control of advanced NSCLC. For example, a previous meta-analysis revealed that treatment with the angiogenesis inhibitor bevacizumab together with the firstline platinum-based chemotherapy was able to significantly prolong the overall survival (OS) and progression-free survival (PFS) of patients with advanced NSCLC. ${ }^{20}$ In the current study, we retrospectively assessed the efficacy of antiangiogenesis therapy with bevacizumab vs chemotherapy alone in advanced NSCLC patients. We reviewed the clinical outcomes, such as clinical efficacy rate, short-term effects, and long-term survival, of advanced NSCLC patients who received chemotherapy plus bevacizumab vs those who received chemotherapy alone. Our findings are expected to facilitate future optimization of such treatments for individual patients.

\section{Patients and methods \\ Patients}

In this study, we retrospectively collected and analyzed the data of 1,352 patients with advanced NSCLC who were treated in Shandong Cancer Hospital and Institute between January 2012 and October 2014. All patients were diagnosed with advanced NSCLC according to the lung cancer tumor node metastasis (TNM) system ${ }^{21}$ and were not suitable for surgical resection of cancerous lesions. The patients received chemotherapy, chemotherapy plus bevacizumab, or supportive care (Figure 1). Chemotherapy included paclitaxel, docetaxel, pemetrexed, gemcitabine, vinorelbine, or one of these combinations with platinum as the first-line, secondline, or maintenance therapy.

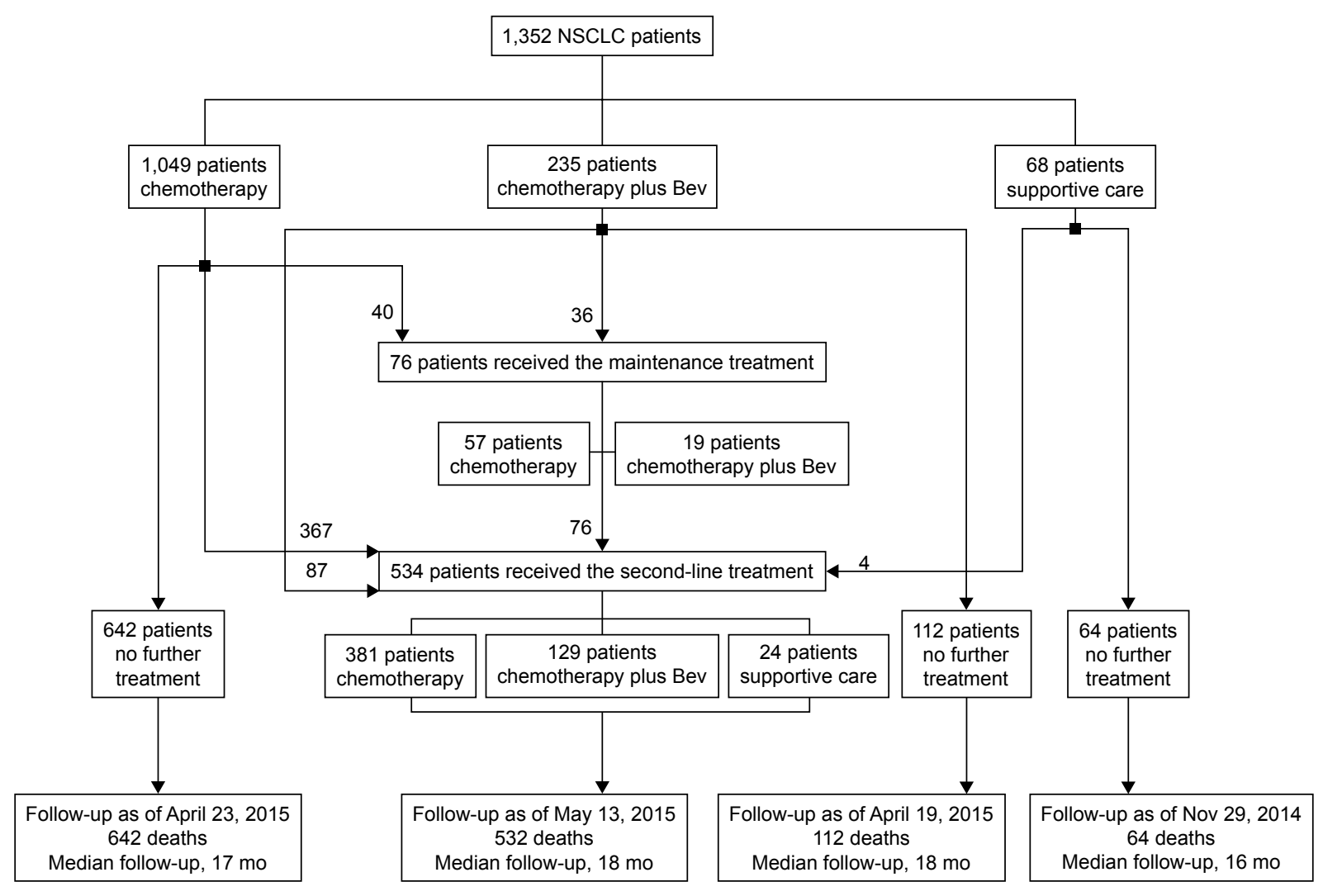

Figure I Illustration of patient treatment.

Notes: Patients received chemotherapy alone, chemotherapy plus bevacizumab, or supportive care. Chemotherapy included paclitaxel, docetaxel, pemetrexed, gemcitabine, or vinorelbine, or one of these combinations with platinum as the first-line, second-line, or maintenance therapy.

Abbreviations: NSCLC, non-small-cell lung cancer; Bev, bevacizumab; mo, months. 
This study was approved by the ethics committee of Shandong Cancer Hospital and Institute. Patient records/information were anonymized and deidentified prior to analysis, and all patients or their guardians signed an informed consent form before participation in this study.

\section{Evaluation of treatment responses}

The treatment responses were recorded based on the Response Evaluation Criteria In Solid Tumors (RECIST) 1.1 guidelines for complete response (CR), partial response (PR), stable disease (SD), or progression of disease (PD). $\mathrm{CR}$ and $\mathrm{PR}$ together were then defined as the remission rate (RR), whereas CR, PR, and SD together were defined as the disease control rate (DCR).

\section{Follow-up of patients}

All patients were followed-up regularly, ie, every month for the first 3 months, every 3 months for the first year, and every 6 months thereafter. The last follow-up was conducted in May 2015. Survival data were collected based on the verification of the vital status of the patients. OS was defined as the time from the date of receiving the first-line chemotherapy to death or last follow-up, whereas PFS was defined as the time from the date of receiving the first-line treatment to disease progression or death.

\section{Statistics analysis}

All statistical analyses were performed using the Statistical Package for the Social Sciences version 17.0 software (SPSS Inc., Chicago, IL, USA). Rates were compared using the $\chi^{2}$ test. Fisher's exact test was performed to analyze categorical variables. The Cox regression model was used to identify independent prognostic factors for patient outcomes in NSCLC, and the median progression-free survival (mPFS) and median overall survival (mOS) were calculated using the Kaplan-Meier curves and statistically analyzed using the log-rank test. A two-sided $P$-value $\leq 0.05$ was considered to be statistically significant.

\section{Results}

\section{Patient characteristics}

The patient characteristics are shown in Table 1. Among the 1,352 patients included in the study, with age ranging between 27 and 88 years (median age, 57 years), 787 were male and 565 were female patients; of which, 1,208 cases were adenocarcinoma and 144 cases were other pathological

Table I Clinicopathological characteristics of patients with different therapeutic regimens

\begin{tabular}{|c|c|c|c|c|c|c|c|c|c|}
\hline Characteristics & $\begin{array}{l}\text { Overall } \\
(n=l, 352)\end{array}$ & $\begin{array}{l}\text { F-A } \\
(n=1,049)\end{array}$ & $\begin{array}{l}\text { F-B } \\
(n=235)\end{array}$ & $\begin{array}{l}\text { F-C } \\
(n=68)\end{array}$ & $\begin{array}{l}\text { S-A } \\
(n=38 I)\end{array}$ & $\begin{array}{l}\text { S-B } \\
(n=129)\end{array}$ & $\begin{array}{l}S-C \\
(n=24)\end{array}$ & $\begin{array}{l}\text { M-A } \\
(n=57)\end{array}$ & $\begin{array}{l}\text { M-B } \\
(n=19)\end{array}$ \\
\hline \multicolumn{10}{|l|}{ Age (years)* } \\
\hline Median & 57 & 57 & 57 & 61 & 56 & 55 & 63 & 57 & 57 \\
\hline Range & $27-88$ & $27-88$ & $30-82$ & $52-81$ & $35-80$ & $27-81$ & $5|-8|$ & $32-75$ & $32-69$ \\
\hline \multicolumn{10}{|l|}{ Sex, n (\%)* } \\
\hline Female & $565(4 I .8)$ & $429(40.9)$ & $100(42.6)$ & $36(52.9)$ & I 78 (46.7) & $69(53.5)$ & $7(29.2)$ & $30(52.6)$ & II (57.9) \\
\hline Male & $787(58.2)$ & $620(59.1)$ & $135(57.4)$ & $32(47.1)$ & $203(53.3)$ & $60(46.5)$ & $17(70.8)$ & $27(47.4)$ & $8(42.1)$ \\
\hline \multicolumn{10}{|c|}{ Histologic type, n (\%)* } \\
\hline Adenocarcinoma & I,208 (89.3) & $94 I(89.4)$ & $215(91.5)$ & $52(76.5)$ & $310(81.4)$ & $108(83.7)$ & $20(83.3)$ & $51(89.5)$ & $17(89.5)$ \\
\hline Other & $144(10.7)$ & $108(10.6)$ & $20(8.5)$ & $16(23.5)$ & $71(18.6)$ & $21(16.3)$ & $4(16.7)$ & $6(10.5)$ & $2(10.5)$ \\
\hline \multicolumn{10}{|c|}{ Site of metastases, n (\%)* } \\
\hline Lung & $56 I(4 I .5)$ & $422(40.2)$ & $100(42.6)$ & $39(57.4)$ & $20 I(52.8)$ & $73(56.6)$ & $12(50.0)$ & $42(73.7)$ & $15(78.9)$ \\
\hline Bone & $476(35.2)$ & $364(34.7)$ & $84(35.7)$ & $28(41.2)$ & $129(33.9)$ & $61(47.3)$ & $9(42.6)$ & $18(31.6)$ & $9(47.4)$ \\
\hline Brain & $411(30.4)$ & $304(29.0)$ & 77 (32.7) & $30(44.1)$ & $102(26.8)$ & $35(27.1)$ & $10(4 \mid .7)$ & $12(21.1)$ & $3(15.8)$ \\
\hline Liver & $247(18.3)$ & $210(20.0)$ & $29(12.3)$ & $8(11.8)$ & $62(16.3)$ & $8(6.2)$ & $2(8.3)$ & $9(15.8)$ & I (5.3) \\
\hline Pleura & $172(12.7)$ & $153(14.6)$ & $17(7.2)$ & $2(2.9)$ & $42(11.0)$ & $5(3.9)$ & I (4.2) & $3(5.3)$ & 0 \\
\hline \multicolumn{10}{|l|}{ Disease stage, n (\%)* } \\
\hline IIIB & $128(9.5)$ & $109(10.4)$ & $19(8.1)$ & 0 & 0 & 0 & 0 & 0 & 0 \\
\hline IV & $1,224(90.5)$ & $940(89.6)$ & $216(91.9)$ & $68(100)$ & $381(100)$ & $129(100)$ & $24(100)$ & $57(100)$ & $19(100)$ \\
\hline \multicolumn{10}{|l|}{ Surgery, n (\%)* } \\
\hline Yes & $3(0.2)$ & $2(0.2)$ & I (0.4) & 0 & $\mathrm{I}(0.3)$ & $\mathrm{I}(0.8)$ & 0 & 0 & I (5.3) \\
\hline No & I,349 (99.8) & I,047 (99.8) & $234(99.6)$ & $68(100)$ & $380(99.7)$ & $128(99.2)$ & $24(100)$ & $57(100)$ & $18(94.7)$ \\
\hline \multicolumn{10}{|l|}{ Radiotherapy, n (\%)* } \\
\hline Yes & $395(29.2)$ & $279(26.6)$ & $86(36.6)$ & 0 & $23(6.0)$ & $7(5.4)$ & 0 & 0 & 0 \\
\hline No & $957(70.8)$ & $770(73.4)$ & $149(63.4)$ & $68(100)$ & $358(94.0)$ & $122(94.6)$ & $24(100)$ & $57(100)$ & $19(100)$ \\
\hline
\end{tabular}

Note: $* P>0.05$ for comparing groups $A, B$, and $C$ in each subgroup.

Abbreviations: $F$, first-line treatment; $S$, second-line treatment; $M$, maintenance treatment; $A$, patients who were treated with chemotherapy without bevacizumab; $B$, patients who were treated with chemotherapy with bevacizumab; C, patients who were treated with supportive care. 
subtypes. All patients were diagnosed with advanced NSCLC, and the most common metastatic sites were lungs (41.5\%), bone (35.2\%), brain (30.4\%), and liver (18.3\%). According to the treatment regimens, we divided the patients into eight groups for receiving the first-line, second-line, and maintenance treatments (Table 1 and Figure 1). The patients treated with chemotherapy alone as the first-line treatment are the F-A group; treated with chemotherapy plus bevacizumab as the first-line treatment the F-B group; treated with supportive care only as the firstline treatment the F-C group; treated with chemotherapy alone as the second-line treatment the S-A group; treated with chemotherapy plus bevacizumab as the second-line treatment the S-B group; treated with supportive care only as the second-line treatment the S-C group; treated with chemotherapy alone as the maintenance treatment the M-A group; and patients treated with chemotherapy plus bevacizumab as the maintenance treatment are the M-B group. Cox multivariate regression analysis showed that age $(P=0.015$ and $P=0.036)$ and performance status $(P<0.01$ and $P<0.01)$ were independent predictors for OS and PFS, respectively (Table 2 ).

\section{Toxicity and feasibility of treatment}

No grade 3/4 adverse reactions were observed among the different treatment regimens, even in patients aged 80 years or older. Grade 2 adverse reactions are described in Table 3. In brief, only the incidence of neutropenia, observed in the group receiving chemotherapy regimen as the first-line treatment, was significantly higher than in the group receiving bevacizumab treatment $(P<0.05)$. The adverse reactions associated with bevacizumab, such as hypertension, proteinuria, hemoptysis, and epistaxis, were rare and rated only as grade 2 reactions.

Table 2 Multivariate analysis of OS and PFS

\begin{tabular}{llll}
\hline Parameter & HR & $\mathbf{9 5 \%} \mathbf{C l}$ & P-value \\
\hline PFS (N=I,352 & & & \\
Sex & I.II & $0.774-I .870$ & 0.67 \\
Age & 0.68 & $0.649-1.397$ & 0.036 \\
Performance status & 1.28 & $0.897-1.829$ & 0.17 \\
Stage of tumor & 0.67 & $1.768-2.618$ & $<0.01$ \\
Histologic type & 1.42 & $0.674-1.870$ & 0.65 \\
OS (N=I,352) & & & \\
Sex & 1.17 & $0.866-1.465$ & 0.43 \\
Age & 0.49 & $0.760-1.467$ & 0.015 \\
Performance status & 0.76 & $0.749-1.618$ & $<0.01$ \\
Stage of tumor & 1.11 & $0.674-I .870$ & 0.087 \\
Histologic type & 0.94 & $0.876-1.175$ & 0.59 \\
\hline
\end{tabular}

Abbreviations: PFS, progression-free survival; OS, overall survival; $\mathrm{Cl}$, confidence interval; HR, hazards ratio.

\section{Association between the first-line therapy and survival in all I,352 patients}

We first assessed and compared the survival data for these patients after the first-line therapy and found that the MPFS and mOS in the group that received bevacizumab plus chemotherapy were 11.5 months $(95 \%$ confidence interval [CI] 10.7-12.3 months) and 17.0 months (95\% CI 15.7-18.3 months), respectively, and these durations were significantly longer than those achieved with chemotherapy alone (7.0 months, 95\% CI 6.6-7.4 months and 14 months; 95\% CI 13.6-14.3 months, respectively; $P<0.01$ ). The mPFS and mOS with supportive care were only 2.0 months (95\% CI: $1.6-2.4$ months) and 4.0 months (95\% CI 3.2-4.8 months), respectively. The Kaplan-Meier curves for the PFS and OS of the different therapeutic groups are shown in Figure 2.

\section{Association between the second-line regimen and survival in 534 patients}

We further analyzed the curative effects of the second-line regimens, and the data are shown in Table 4 and Figure 3C. The overall response to the second-line treatment was higher in the bevacizumab plus chemotherapy group than in the chemotherapy only group ( $31.8 \%$ vs $25.5 \%, P<0.05)$, but the DCR did not differ significantly between the two groups. The mPFS with bevacizumab plus chemotherapy was 3.0 months (95\% CI 2.8-3.2 months), which was higher than that obtained with chemotherapy alone (2.0 months, $95 \% \mathrm{CI}$ 1.8-2.1 months; $P<0.01)$. The mPFS with supportive care was only 1.5 months ( $95 \%$ CI $1.3-1.6$ months).

\section{Association between the maintenance regimen and survival in 76 patients}

The $\mathrm{mPFS}$ and $\mathrm{mOS}$ of the group receiving bevacizumab plus chemotherapy as the maintenance therapy were 6.0 months (95\% CI 4.5-7.4 months) and 17.4 months (95\% CI 16.4-18.4 months), respectively, durations which were statistically longer than those achieved with chemotherapy alone (3.0 months, 95\% CI 2.6-3.4 months and 15.0 months; $95 \%$ CI 14.9-15.1 months, $P<0.01$; Figure $3 \mathrm{~A}$ and $\mathrm{B}$ ).

\section{Discussion}

Clinically, stage IIIB or IV disease or T4N2M0/TanyN3M0/ TanyNanyM1 disease is considered as advanced-stage NSCLC, and each condition is associated with metastasis. These patients are usually treated with chemotherapy and radiation therapy, and more recently with targeted therapy, which also helps to control the disease progression 
Table 3 Association of adverse reactions with therapeutic regimens

\begin{tabular}{|c|c|c|c|c|c|c|c|c|c|}
\hline $\begin{array}{l}\text { Adverse reaction, } \\
\text { grade } 2\end{array}$ & $\begin{array}{l}\text { F-A }(n=I, 049), \\
n(\%)\end{array}$ & $\begin{array}{l}\text { F-B (n=235), } \\
\text { n (\%) }\end{array}$ & $P$-value & $\begin{array}{l}\text { S-A (n=38I), } \\
n(\%)\end{array}$ & $\begin{array}{l}\text { S-B }(n=\mid 29), \\
n(\%)\end{array}$ & $P$-value & $\begin{array}{l}\text { M-A (n=57), } \\
\text { n (\%) }\end{array}$ & $\begin{array}{l}\text { M-B (n=I9), } \\
\text { n (\%) }\end{array}$ & $P$-value \\
\hline \multicolumn{10}{|l|}{ Hematological } \\
\hline Neutropenia & $429(40.9)$ & $66(28.1)$ & $<0.01$ & I43 (37.5) & $40(31.0)$ & $>0.05$ & $24(42.1)$ & $8(42.1)$ & $>0.05$ \\
\hline Anemia & $125(11.9)$ & $25(10.6)$ & $>0.05$ & $4 \mathrm{I}(10.8)$ & $13(10.0)$ & $>0.05$ & $6(10.5)$ & $3(15.8)$ & $>0.05$ \\
\hline Thrombocytopenia & $25 I(23.9)$ & $51(21.7)$ & $>0.05$ & $81(21.3 \%)$ & $26(20.2)$ & $>0.05$ & $10(17.5)$ & $3(15.8)$ & $>0.05$ \\
\hline \multicolumn{10}{|l|}{ Nonhematological } \\
\hline Asthenia & $566(54.0)$ & $108(46.0)$ & 0.026 & $185(48.6)$ & $53(4 I . I)$ & $>0.05$ & $30(52.6)$ & II (57.9) & $>0.05$ \\
\hline Anorexia & $520(49.6)$ & II 5 (48.9) & $>0.05$ & $162(42.5)$ & 54 (4I.9) & $>0.05$ & $26(45.6)$ & $8(42 . I)$ & $>0.05$ \\
\hline Vomiting & $59(5.6)$ & $14(6.0)$ & $>0.05$ & $20(5.2)$ & $6(4.7)$ & $>0.05$ & $3(5.3)$ & I (5.3) & $>0.05$ \\
\hline Diarrhea & $55(5.2)$ & $9(3.8)$ & $>0.05$ & $17(4.5)$ & $5(3.9)$ & $>0.05$ & $3(5.3)$ & $2(10.5)$ & $>0.05$ \\
\hline Constipation & $380(40.9)$ & $82(34.9)$ & $>0.05$ & $|2|(3 \mid .8)$ & $40(31.0)$ & $>0.05$ & $11(19.3)$ & $3(15.8)$ & $>0.05$ \\
\hline Rash & $58(5.5)$ & $10(4.3)$ & $>0.05$ & $19(5.0)$ & $7(5.4)$ & $>0.05$ & $3(5.3)$ & I (5.3) & $>0.05$ \\
\hline Weight loss ( $\geq 3 \mathrm{~kg}$ ) & $77(7.3)$ & $23(9.8)$ & $>0.05$ & 15 & $5(3.9)$ & $>0.05$ & $12(21.1)$ & $4(2 I . I)$ & $>0.05$ \\
\hline \multicolumn{10}{|l|}{ Bev-associated } \\
\hline Hypertension & $\mathrm{I}(0.1)$ & $2(0.9)$ & & 0 & $\mathrm{I}(0.8)$ & & 0 & I (5.3) & \\
\hline Proteinuria & $\mathrm{I}(0.1)$ & $7(3.0)$ & & 0 & $4(3.1)$ & & 0 & $2(10.5)$ & \\
\hline Hemoptysis & 0 & $\mathrm{I}(0.4)$ & & 0 & 0 & & 0 & 0 & \\
\hline Epistaxis & 0 & $3(1.3)$ & & 0 & $\mathrm{I}(0.8)$ & & 0 & 0 & \\
\hline
\end{tabular}

Abbreviations: Bev, bevacizumab; F, first-line treatment; S, second-line treatment; $M$, maintenance treatment; $A$, patients who were treated with chemotherapy without bevacizumab; $B$, patients who were treated with chemotherapy with bevacizumab.

and improve patients' quality of life. NSCLC often first metastasizes to the lymph nodes and then leads to distant metastasis to other organs, such as the brain, bone, or liver. The underlying mechanism for NSCLC metastasis remains to be fully determined. A previous study by Fokas et al reported the mechanism of NSCLC metastasis to the brain and demonstrated that the whole process is divided into six basic steps: tumor cell escape from the primary site, dissemination in the circulation system, adhesion to the vascular wall, extravasation (penetration of the blood-brain barrier into the brain parenchyma), interaction with the brain microenvironment, and survival and growth of a secondary tumor. ${ }^{22}$ Among these steps, tumor angiogenesis is a critical factor for tumor cells to establish a metastatic colony in a distant organ, ${ }^{23}$
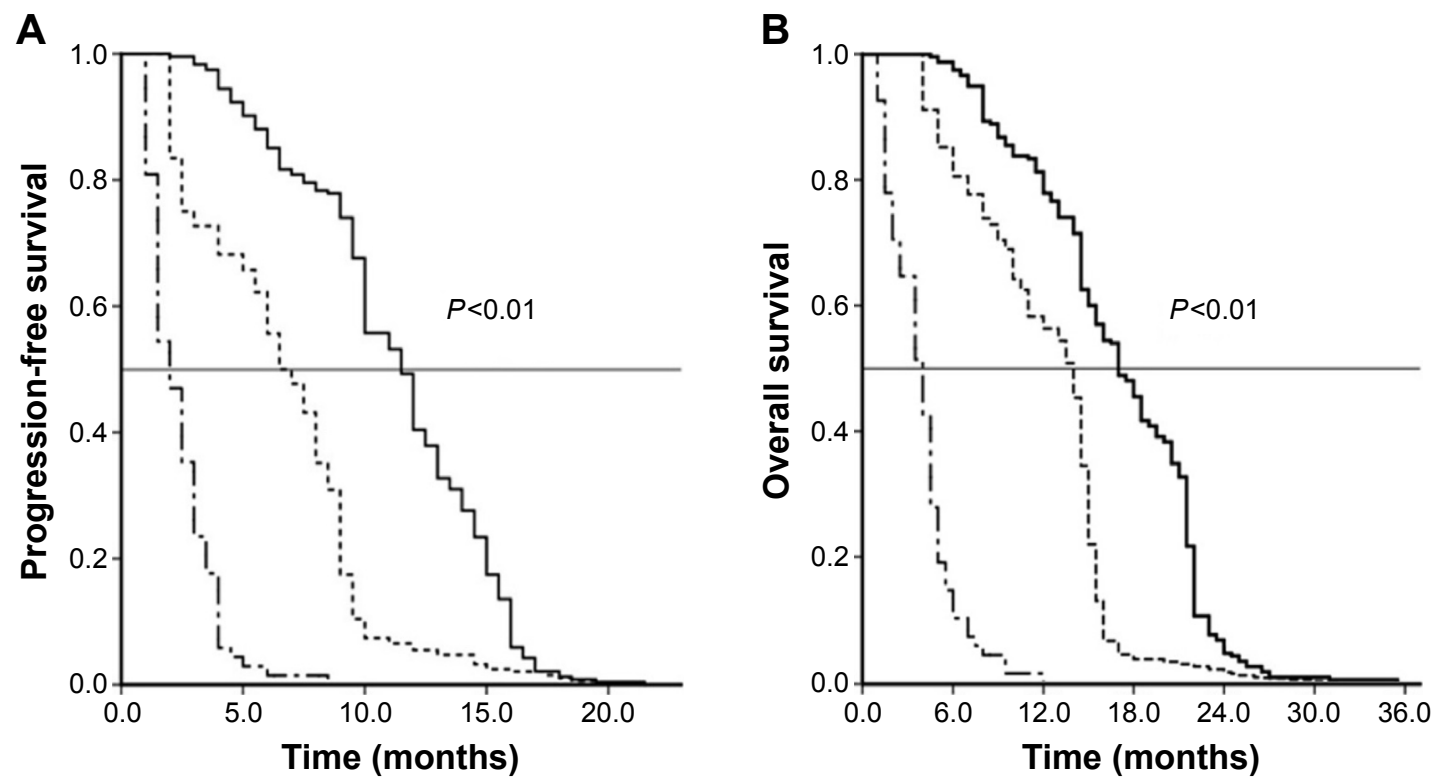

$\sim$ Supportive treatment $\quad$-I Chemotherapy $\rightarrow$ Bevacizumab

Figure 2 Kaplan-Meier curves for each treatment regimen.

Notes: (A) PFS and (B) OS of I,352 patients according to the first-line treatment.

Abbreviations: PFS, progression-free survival; OS, overall survival. 
Table 4 Response of patients to second-line treatment

\begin{tabular}{|c|c|c|c|}
\hline Response & S-A (n=38I), n (\%) & S-B (n=129), n (\%) & $P$-value \\
\hline \multicolumn{4}{|c|}{ First therapeutic evaluation } \\
\hline PR & $97(25.5)$ & $4 \mathrm{I}(31.8)$ & $<0.05$ \\
\hline$C R+P R$ & $97(25.5)$ & $4 \mathrm{l}(31.8)$ & $<0.05$ \\
\hline SD & $142(37.3)$ & $45(34.9)$ & $>0.05$ \\
\hline DCR & $239(62.8)$ & $86(66.7)$ & $>0.05$ \\
\hline PD & $142(37.2)$ & $43(33.3)$ & $>0.05$ \\
\hline \multicolumn{4}{|c|}{ Second therapeutic evaluation } \\
\hline PR & $80(21.0)$ & $33(25.6)$ & $>0.05$ \\
\hline$C R+P R$ & $80(21.0)$ & $33(25.6)$ & $>0.05$ \\
\hline SD & $84(22.0)$ & $31(24.0)$ & $>0.05$ \\
\hline DCR & $164(43.0)$ & $64(49.6)$ & $>0.05$ \\
\hline PD & $217(57.0)$ & $65(50.4)$ & $>0.05$ \\
\hline
\end{tabular}

Abbreviations: $C R$, complete remission; $P R$, partial remission; $S D$, stable disease; $\mathrm{PD}$, progressive disease; $\mathrm{DCR}$, disease control rate; $\mathrm{S}$, second-line treatment; $A$, patients who were treated with chemotherapy without bevacizumab; $B$, patients who were treated with chemotherapy with bevacizumab.

which provides a mechanistic basis for anti-angiogenesis therapy in the treatment of NSCLC with brain metastasis.

Bevacizumab, one of the first agents used for anti-angiogenesis therapy, is a recombinant, humanized monoclonal antibody that can block angiogenesis by inhibiting vascular endothelial growth factor A (VEGF-A). Bevacizumab was approved by the US Food and Drug Administration (FDA) in 2004 for use in treating metastatic colon cancer ${ }^{24}$ and in 2006 as a first-line treatment for advanced nonsquamous cell NSCLC in combination with carboplatin/ paclitaxel chemotherapy. ${ }^{25}$ The FDA also authorized medical oncologists to utilize bevacizumab in combination with a platinum-based doublet regimen as a first-line treatment for patients with unresectable, locally advanced, recurrent, or metastatic NSCLC. ${ }^{25-28}$ The addition of bevacizumab to
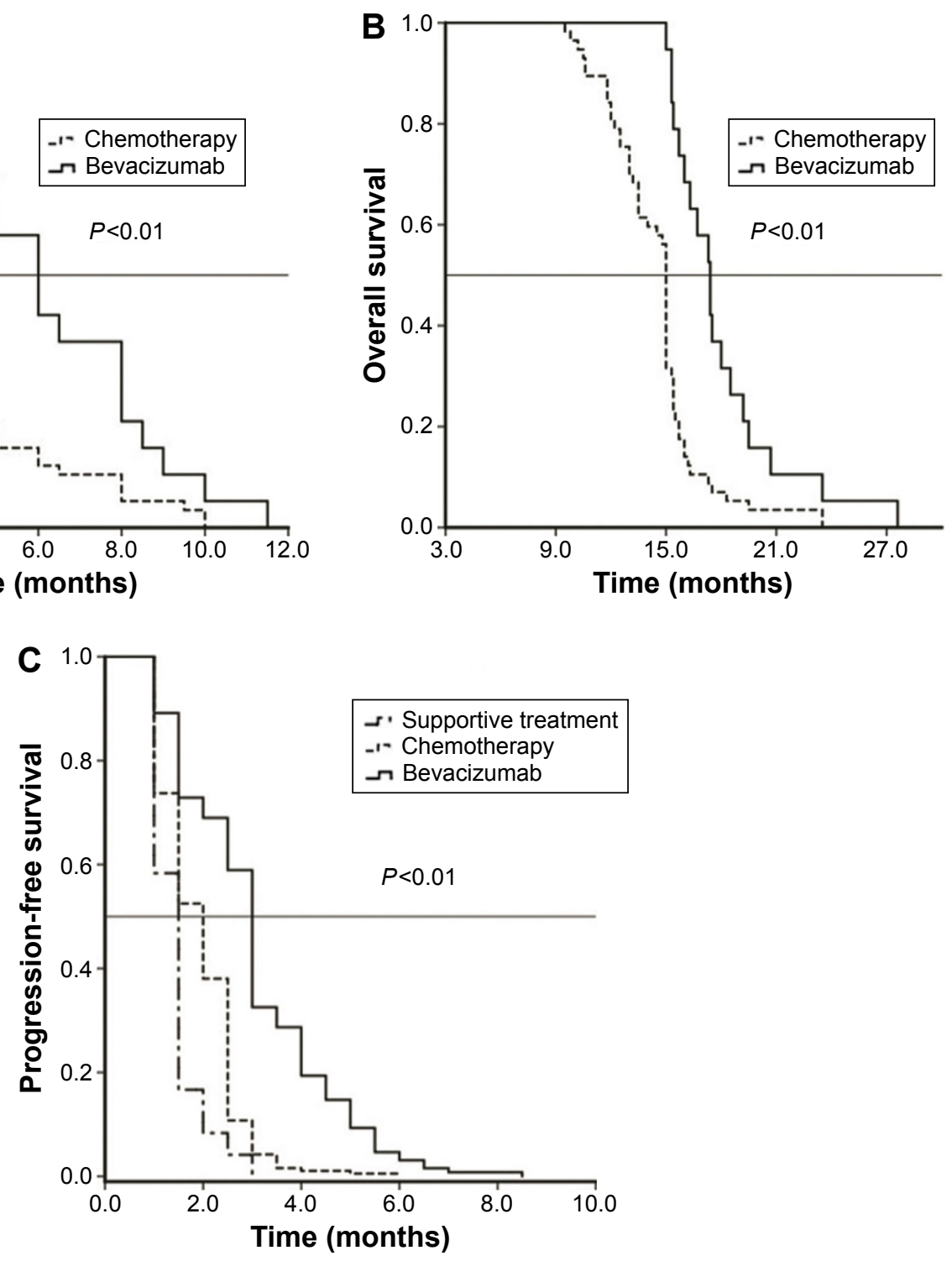

Figure 3 Kaplan-Meier estimates of (A) PFS and (B) OS in 76 patients who received maintenance therapy and (C) PFS after second-line treatment in 534 patients. Abbreviations: PFS, progression-free survival; OS, overall survival. 
carboplatin and paclitaxel for NSCLC treatment was shown to significantly improve the OS and PFS compared to carboplatin/paclitaxel alone in an Eastern Cooperative Oncology Group (ECOG) Phase III study. ${ }^{25}$ The OS of patients who received a standard chemotherapy regimen (carboplatin/ paclitaxel alone) was 10.3 months, whereas that among patients who received a standard chemotherapy regimen plus bevacizumab was 12.3 months in the E4599 trial. ${ }^{29}$ The PFS in the patients with nonsquamous cell NSCLC also was significantly better (4.5 vs 6.2 months), and the PFS in adenocarcinoma patients was 5 vs 6.6 months. Similar results were also achieved in another large randomized Phase III clinical trial (AVAiL). ${ }^{30}$ In our current study, we found that bevacizumab in combination with chemotherapy improved the RR and significantly extended the PFS and OS compared to those in the control group (chemotherapy alone). Our study further confirmed the effectiveness of bevacizumab in combination with chemotherapy for patients with advanced NSCLC, especially in lung adenocarcinoma patients.

Furthermore, the most common side effect of bevacizumab therapy was bleeding, which is most likely related to the inhibitory effects on VEGF in the vascular endothelium. For example, Ferrara reported that the maintenance and survival of immature blood vessels rely on VEGF expression. ${ }^{31}$ In addition, proteinuria, ${ }^{32}$ hypertension, ${ }^{33,34}$ and neutropenia ${ }^{35,36}$ were also considered to be common adverse reactions. Moreover, other uncommon toxicities, such as gastrointestinal perforation, have been observed in the clinical trials of bevacizumab treatment for patients with NSCLC..$^{29,37}$ In our current study, we did not observe any $3 / 4$ grade adverse reactions or cerebrovascular accidents in any of the 1,352 patients, although we did observe other adverse reactions associated with bevacizumab therapy, such as hypertension, proteinuria, hemoptysis, and epistaxis. The severity of these reactions was only grade 2 , and they could be easily controlled with symptomatic treatment. We consider that conventional pretreatment, nursing service, and good psychological aid provided in our study were greatly beneficial. However, no serious adverse reactions occurred in these patients after treatment with bevacizumab plus chemotherapy. Thus, none of our patients required a change in the therapeutic regimen due to an adverse reaction, suggesting that chemotherapy plus bevacizumab as the first-line treatment was tolerable.

In addition, previous studies have shown that some patients choose maintenance treatment after the first-line chemotherapy, and the AVAPERL trial demonstrated that bevacizumab/pemetrexed maintenance therapy increased the PFS from 3.7 months to 7.4 months compared to the maintenance therapy with bevacizumab alone, although no significant difference in OS was observed between these two groups. ${ }^{38}$ The PRONOUNCE trial reported similar findings. ${ }^{39}$ Petrioli et al recently reported that maintenance treatment with bevacizumab and vinorelbine after first-line therapy with cisplatin, gemcitabine, and bevacizumab resulted in a better PFS (8.4 months, 95\% CI 4.4-10.7 months) and OS (18.1 months, 95\% CI 15.3-20.8 months). ${ }^{40}$ Our current retrospective analysis showed that both the PFS and OS of patients who received chemotherapy plus bevacizumab as the first-line therapy were better than those who received chemotherapy alone. Chemotherapy plus bevacizumab as the maintenance treatment also showed a better PFS and OS. Furthermore, patients with disease recurrence or progression after the first-line chemotherapy do need a second-line treatment. The best therapeutic regimen for the second-line treatment remains to be determined, and currently, docetaxel, pemetrexed, and EGFR-TKIs are the main recommendations. ${ }^{41-45}$ Our present study showed a curative effect of bevacizumab plus chemotherapy as the second-line treatment in 534 patients (Table 4). Specifically, the RR was higher in the bevacizumab plus chemotherapy group compared to the chemotherapy alone group (31.8\% vs $25.5 \%)$, but the DCR was not statistically significant in the therapeutic evaluations of both the first- and second-line treatments. The mPFS of the group who received bevacizumab plus chemotherapy as the second-line treatment was significantly higher than that of the chemotherapy only group.

\section{Clinical practice points}

Anti-angiogenesis therapy was effective in controlling NSCLC, but the side effects associated with bevacizumab limit its use. There are few reports on maintenance therapy, especially in the People's Republic of China. We found that chemotherapy plus bevacizumab as the first-line and maintenance treatment had a better curative effect and tolerable adverse reactions compared to chemotherapy alone. Bevacizumab combined with cytotoxic drugs was also found to be suitable as a second-line treatment. There were no intolerable adverse reactions associated with bevacizumab even in patients with brain metastases. Therefore, bevacizumab was found to be suitable for advanced NSCLC patients, and the side effects are not cause for great concern.

\section{Limitations}

This study does have some limitations, such as the retrospective nature of the study in a single hospital; therefore, our findings need to be verified in a prospective clinical trial conducted in multiple centers. Future studies should also 
evaluate and associate VEGF2 expression as a surrogate biomarker for the effectiveness of bevacizumab therapy in NSCLC patients.

\section{Conclusion}

The present study evaluated the efficacy of bevacizumab plus chemotherapy vs chemotherapy alone in advanced NSCLC patients and showed that bevacizumab plus chemotherapy as the first-line and maintenance treatment led to much better curative effects and tolerable adverse reactions in patients with advanced NSCLC compared to chemotherapy alone. Bevacizumab in combination with cytotoxic drugs was also suitable as the second-line treatment in Chinese NSCLC patients. Our data further confirmed the results of previous clinical trials with regard to the efficacy of bevacizumab plus chemotherapy in NSCLC patients.

\section{Disclosure}

The authors report no conflicts of interest in this work.

\section{References}

1. Jemal A, Bray F, Center MM, Ferlay J, Ward E, Forman D. Global cancer statistics. CA Cancer J Clin. 2011;61(2):69-90.

2. Siegel R, Naishadham D, Jemal A. Cancer statistics, 2013. CA Cancer J Clin. 2013;63(1):11-30.

3. Ettinger DS, Bepler G, Bueno R, et al. Non-small cell lung cancer clinical practice guidelines in oncology. J Natl Compr Canc Netw. 2006; 4(6):548-582.

4. Scagliotti G, Brodowicz T, Shepherd FA, et al. Treatment-by-histology interaction analyses in three phase III trials show superiority of pemetrexed in nonsquamous non-small cell lung cancer. $J$ Thorac Oncol. 2011;6(1):64-70.

5. Marino P, Pampallona S, Preatoni A, Cantoni A, Invernizzi F. Chemotherapy vs. supportive care in advanced non-small-cell lung cancer. Results of a meta-analysis of the literature. Chest. 1994;106(3): 861-865.

6. Shimokata K. [Chemotherapy in non-small cell lung cancer]. Nihon Geka Gakkai Zasshi. 1997;98(1):41-45. Japanese.

7. Jaakkimainen L, Goodwin PJ, Pater J, Warde P, Murray N, Rapp E. Counting the costs of chemotherapy in a National Cancer Institute of Canada randomized trial in nonsmall-cell lung cancer. JClin Oncol. 1990; 8(8):1301-1309.

8. Maemondo M, Inoue A, Kobayashi K, et al. Gefitinib or chemotherapy for non-small-cell lung cancer with mutated EGFR. $N$ Engl J Med. 2010;362(25):2380-2388.

9. Mitsudomi T, Morita S, Yatabe Y, et al. Gefitinib versus cisplatin plus docetaxel in patients with non-small-cell lung cancer harbouring mutations of the epidermal growth factor receptor (WJTOG3405): an open label, randomised phase 3 trial. Lancet Oncol. 2010;11(2):121-128.

10. Casaluce F, Sgambato A, Maione P, et al. ALK inhibitors: a new targeted therapy in the treatment of advanced NSCLC. Target Oncol. 2013; 8(1):55-67.

11. Shaw AT, Kim DW, Nakagawa K, et al. Crizotinib versus chemotherapy in advanced ALK-positive lung cancer. N Engl J Med. 2013;368(25): 2385-2394.

12. Solomon BJ, Mok T, Kim DW, et al. First-line crizotinib versus chemotherapy in ALK-positive lung cancer. N Engl J Med. 2014; 371(23):2167-2177.
13. Blackhall F, Kim DW, Besse B, et al. Patient-reported outcomes and quality of life in PROFILE 1007: a randomized trial of crizotinib compared with chemotherapy in previously treated patients with ALKpositive advanced non-small-cell lung cancer. J Thorac Oncol. 2014; 9(11):1625-1633.

14. Shi Y, Au JS, Thongprasert S, et al. A prospective, molecular epidemiology study of EGFR mutations in Asian patients with advanced non-small-cell lung cancer of adenocarcinoma histology (PIONEER). J Thorac Oncol. 2014;9(2):154-162.

15. Li Y, Li Y, Yang $\mathrm{T}$, et al. Clinical significance of EML4-ALK fusion gene and association with EGFR and KRAS gene mutations in 208 Chinese patients with non-small cell lung cancer. PLoS One. 2013;8(1):e52093.

16. Zhang X, Zhang S, Yang X, et al. Fusion of EML4 and ALK is associated with development of lung adenocarcinomas lacking EGFR and KRAS mutations and is correlated with ALK expression. Mol Cancer. 2010;9:188.

17. An SJ, Chen $\mathrm{ZH}$, Su J, et al. Identification of enriched driver gene alterations in subgroups of non-small cell lung cancer patients based on histology and smoking status. PLoS One. 2012;7(6):e40109.

18. Takeuchi K, Choi YL, Soda M, et al. Multiplex reverse transcriptionPCR screening for EML4-ALK fusion transcripts. Clin Cancer Res. 2008;14(20):6618-6624.

19. Koivunen JP, Mermel C, Zejnullahu K, et al. EML4-ALK fusion gene and efficacy of an ALK kinase inhibitor in lung cancer. Clin Cancer Res. 2008;14(13):4275-4283.

20. Soria JC, Mauguen A, Reck M, et al. Systematic review and metaanalysis of randomised, phase II/III trials adding bevacizumab to platinum-based chemotherapy as first-line treatment in patients with advanced non-small-cell lung cancer. Ann Oncol. 2013; 24(1):20-30.

21. Goldstraw P, Crowley J, Chansky K, et al. The IASLC Lung Cancer Staging Project: proposals for the revision of the TNM stage groupings in the forthcoming (seventh) edition of the TNM Classification of malignant tumours. J Thorac Oncol. 2007;2(8):706-714.

22. Fokas E, Steinbach JP, Rodel C. Biology of brain metastases and novel targeted therapies: time to translate the research. Biochim Biophys Acta. 2013;1835(1):61-75.

23. Kienast Y, von Baumgarten L, Fuhrmann M, et al. Real-time imaging reveals the single steps of brain metastasis formation. Nat Med. 2010; 16(1):116-122.

24. Hurwitz H, Fehrenbacher L, Novotny W, et al. Bevacizumab plus irinotecan, fluorouracil, and leucovorin for metastatic colorectal cancer. N Engl J Med. 2004;350(23):2335-2342.

25. Sandler A, Gray R, Perry MC, et al. Paclitaxel-carboplatin alone or with bevacizumab for non-small-cell lung cancer. N Engl J Med. 2006; 355(24):2542-2550.

26. Ryan MS, Yentz SE, Patel JD. Bevacizumab in advanced NSCLC: chemotherapy partners and duration of use. Curr Treat Options in Oncol. 2013;14(4):595-609.

27. Liu KJ, Wu HY. A retrospective analysis of cisplatin, pemetrexed, and bevacizumab in previously treated non-small-cell lung cancer. Oncotarget. 2015;6(26):22750-22757.

28. Lima AB, Macedo LT, Sasse AD. Addition of bevacizumab to chemotherapy in advanced non-small cell lung cancer: a systematic review and meta-analysis. Plos One. 2011;6(8):e22681.

29. Sandler A, Yi J, Dahlberg S, et al. Treatment outcomes by tumor histology in eastern cooperative group study e4599 of bevacizumab with paclitaxel/carboplatin for advanced non-small cell lung cancer. J Thorac Oncol. 2010;5(9):1416-1423.

30. Reck M, von Pawel J, Zatloukal P, et al. Phase III trial of cisplatin plus gemcitabine with either placebo or bevacizumab as first-line therapy for nonsquamous non-small-cell lung cancer: AVAil. J Clin Oncol. 2009;27(8):1227-1234.

31. Ferrara N. VEGF: an update on biological and therapeutic aspects. Curr Opin Biotechnol. 2000;11(6):617-624. 
32. Miller KD, Chap LI, Holmes FA, et al. Randomized phase III trial of capecitabine compared with bevacizumab plus capecitabine in patients with previously treated metastatic breast cancer. J Clin Oncol. 2005;23(4):792-799.

33. Kamba T, McDonald DM. Mechanisms of adverse effects of anti-VEGF therapy for cancer. Br J Cancer. 2007;96(12):1788-1795.

34. Bennouna J, von Powel J, Zatloukal P, Manegold C. Management of hypertension (HTN) in patients with advanced or recurrent non-squamous non-small cell lung cancer (NSCLC) receiving first-line cisplatin and gemcitabine with bevacizumab or placeboresults from randomised phase III trial BO17704. EJC Suppl. 2007; 5(359):abstract 6509.

35. Bennouna J, von Powel J, Zatloukal P, Manegold C. Efficacy and safety results from $\mathrm{BO} 17704$, a randomised, placebo-controlled phase III study of bevacizumab in combination with cisplatin and gemcitabine in patients with advanced or recurrent non-squamous non-small cell lung cancer (NSCLC). EJC Suppl. 2007;5(357):abstract 6503.

36. Dansin É, Cousin S, Lauridant G, Mennecier B. [Bevacizumab in thoracic oncology: results and practical aspects]. Rev Pneumol Clin. 2013;69(3):159-169. French.

37. Avastin $^{\circledR}$ (bevacizumab) [package insert]. Avastin Summary of Product Characteristics. South San Francisco, CA: Genentech, Inc; 2007. Available from: http://www.emea. europa.eu/humandocs/PDFs/EPAR/ avastin/H-582-PI-en.pdf

38. Barlesi F, Scherpereel A, Rittmeyer A, et al. Randomized phase III trial of maintenance bevacizumab with or without pemetrexed after first-line induction with bevacizumab, cisplatin, and pemetrexed in advanced nonsquamous non-small-cell lung cancer: AVAPERL (MO22089). J Clin Oncol. 2013;31(24):3004-3011.

39. Zinner RG, Obasaju CK, Spigel DR, et al. PRONOUNCE: randomized, open-label, phase III study of first-line pemetrexed + carboplatin followed by maintenance pemetrexed versus paclitaxel + carboplatin + bevacizumab followed by maintenance bevacizumab in patients ith advanced nonsquamous non-small-cell lung cancer. J Thorac Oncol. 2015;10(1):134-142.
40. Petrioli R, Francini E, Fiaschi AI, et al. Switch maintenance treatment with oral vinorelbine and bevacizumab after induction chemotherapy with cisplatin, gemcitabine and bevacizumab in patients with advanced non-squamous non-small cell lung cancer: a phase II study. Med Oncol. 2015;32(4):134.

41. Shepherd FA, Dancey J, Ramlau R, et al. Prospective randomized trial of docetaxel versus best supportive care in patients with non-small-cell lung cancer previously treated with platinum-based chemotherapy. J Clin Oncol. 2000;18(10):2095-2103.

42. Hanna N, Shepherd FA, Fossella FV, et al. Randomized phase III trial of pemetrexed versus docetaxel in patients with non-small-cell lung cancer previously treated with chemotherapy. J Clin Oncol. 2004; 22(9):1589-1597.

43. Paz-Ares LG, Altug S, Vaury AT, et al. Treatment rationale and study design for a phase III, double-blind, placebo-controlled study of maintenance pemetrexed plus best supportive care versus best supportive care immediately following induction treatment with pemetrexed plus cisplatin for advanced nonsquamous non-small cell lung cancer. $B M C$ Cancer. 2010;10:85.

44. Passaro A, Cortesi E, de Marinis F. Second-line treatment of non-smallcell lung cancer: chemotherapy or tyrosine kinase inhibitors? Expert Rev Anticancer Ther. 2011;11(10):1587-1597.

45. Heigener DF, Wu YL, van Zandwijk N, et al. Second-line erlotinib in patients with advanced non-small-cell lung cancer: subgroup analyses from the TRUST study. Lung Cancer. 2011;74(2):274-279.
OncoTargets and Therapy

\section{Publish your work in this journal}

OncoTargets and Therapy is an international, peer-reviewed, open access journal focusing on the pathological basis of all cancers, potential targets for therapy and treatment protocols employed to improve the management of cancer patients. The journal also focuses on the impact of management programs and new therapeutic agents and protocols on

\section{Dovepress}

patient perspectives such as quality of life, adherence and satisfaction. The manuscript management system is completely online and includes a very quick and fair peer-review system, which is all easy to use. Visit http://www.dovepress.com/testimonials.php to read real quotes from published authors. 